\title{
Author Correction: Genome-wide meta-analysis, fine-mapping and integrative prioritization implicate new Alzheimer's disease risk genes
}

Jeremy Schwartzentruber (D), Sarah Cooper, Jimmy Z. Liu, Inigo Barrio-Hernandez (D), Erica Bello, Natsuhiko Kumasaka (D, Adam M. H. Young, Robin J. M. Franklin, Toby Johnson, Karol Estrada, Daniel J. Gaffney (D), Pedro Beltrao (D) and Andrew Bassett iD

Correction to: Nature Genetics https://doi.org/10.1038/s41588-020-00776-w, published online 15 February 2021.

In the version of this article initially published, in Fig. 2, the column showing the number of colocalizations at the far-right side of the figure contained incorrect values, and the red circles denoting them were missing. The error has been corrected in the HTML and PDF versions of the article.

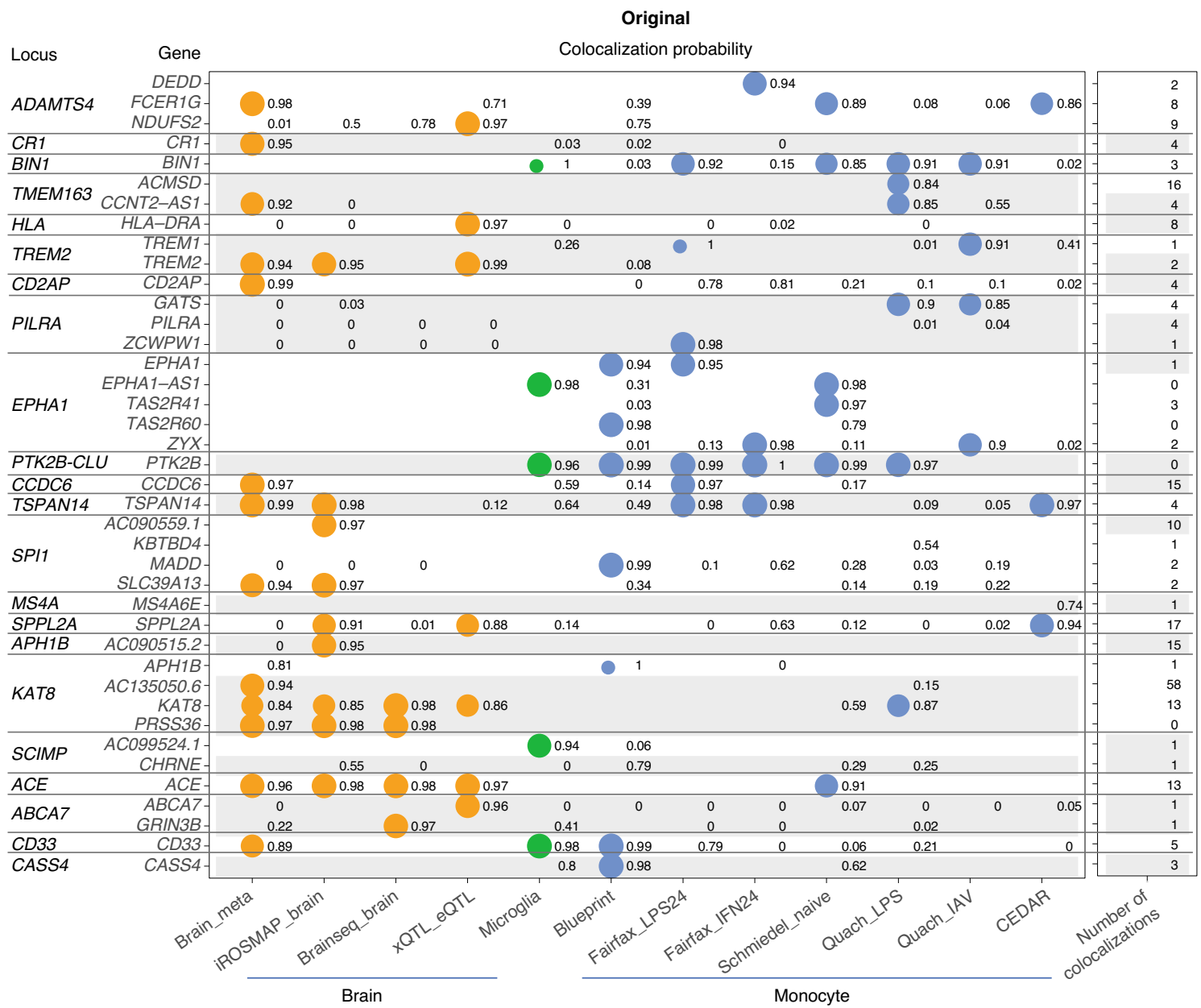




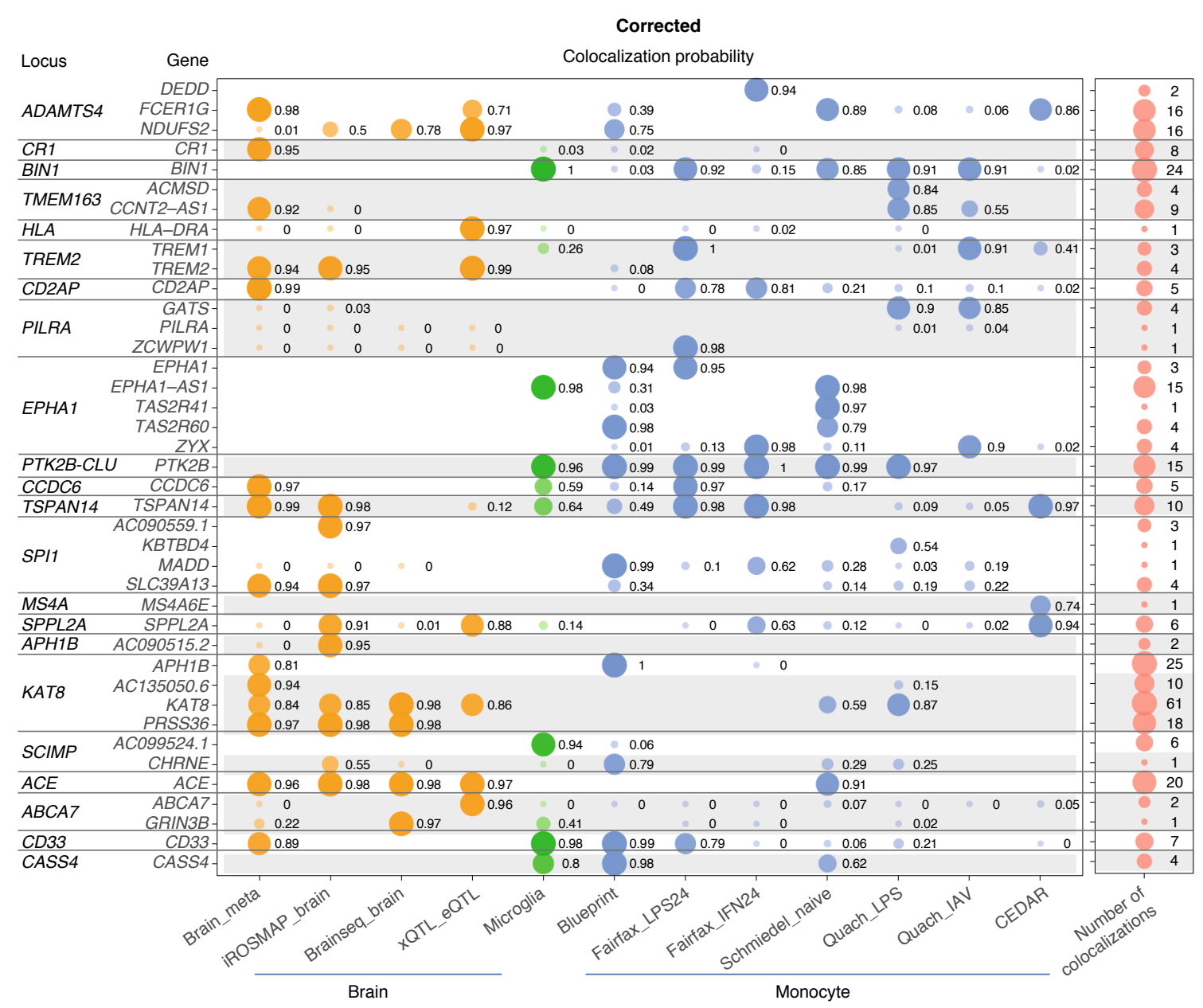

Fig. 2 | Original and corrected.

Published online: 26 February 2021

https://doi.org/10.1038/s41588-021-00822-1

() The Author(s), under exclusive licence to Springer Nature America, Inc. 2021

\section{Author Correction: Transcription factor competition at the $\boldsymbol{\gamma}$-globin promoters controls hemoglobin switching}

Nan Liu, Shuqian Xu, Qiuming Yao, Qian Zhu ID, Yan Kai, Jonathan Y. Hsu D, Phraew Sakon, Luca Pinello (D), Guo-Cheng Yuan (D), Daniel E. Bauer (D) and Stuart H. Orkin D

Correction to: Nature Genetics https://doi.org/10.1038/s41588-021-00798-y, published online 1 March 2021.

In the version of this article initially published, in the funding for author Stuart H. Orkin in the Acknowledgements, 'Burroughs Wellcome Fund' should have read 'Doris Duke Charitable Foundation'. The error has been corrected in the HTML and PDF versions of the article.

Published online: 17 March 2021

https://doi.org/10.1038/s41588-021-00834-X

(c) The Author(s), under exclusive licence to Springer Nature America, Inc. 2021 